「材料」 (Journal of the Society of Materials Science, Japan), Vol. 67, No. 6, pp. 646-652, June 2018

Original Papers

\title{
Studying Factors Affecting Fusion Pool Geometry of Micro Plasma Arc which Remelts Austenitic Stainless Steel Sheets (AISI 316L) by Using Response Surface Method
}

by

\author{
Mohsen ALI*, Ahmad ALMALEH* and Ahmed RASSIS*
}

Micro Plasma Arc welding is used to remelt thin sheets of austenitic stainless steel (AISI 316L) 1mm. In this article the effects of micro plasma factors $(2.4 \mathrm{~mm}$ electrode diameter) on fusion pool geometry parameters namely width, height and HAZ's width of austenitic stainless steel sheets are analyzed. The mathematical models have been developed by response surface method, in which three factors, three levels and central composite design were used to develop mathematical models, incorporating micro plasma parameters and fusion pool geometry. The adequacy of the models was checked by ANOVA technique. Variations of output responses with input process variables were discussed in both effects: main and interaction. As a result, fusion pool geometry parameters can be estimated by using the developed mathematical models.

\section{Key words:}

Micro plasma arc welding, Fusion pool geometry, ANOVA, Response surface method

\section{Introduction}

Welding thin sheets plays an important role in reducing structure weight which has gained importance in several engineering fields ${ }^{1}$. Austenitic stainless steel has excellent strength and good ductility at high temperature. Such as that is used in aircraft, aerospace, and in medical industry, where it is subject to high temperature and corrosive environment ${ }^{2}$.

Plasma arc welding (PAW) is a constricting arc welding process; it is brought to the industry by providing an advanced level of control and accuracy to produce high quality products. From the literature review ${ }^{3)-11)}$, it was understood that many researchers studied the influence of PAW process parameters on bead geometry using statistical techniques like Taguchi method, response surface method (RSM), artificial neural network and genetic algorithm. However, in all the works reported so far researchers have concentrated on thick materials; but not much effort was made to develop mathematical models to predict the models especially when welding thin stainless steel sheets in a flat position. An attempt is made to correlate important micro PAW (MPAW) process parameters to remelt fusion pool geometry of AISI 316L stainless steel sheets by developing mathematical models using statistical tools.

\section{Experimental Setup}

\subsection{Materials and Methodology}

AISI 316L stainless steel sheets of $100 \times 50 \times 1 \mathrm{~mm}$ were used. A fusion pool autogenously was formed with MPAW process through central long line $(100 \mathrm{~mm})$. The chemical composition of AISI 316 L stainless steel sheet is given in
Table 1. High purity argon gas (99.99\%) was used as both a shielding gas and a trailing gas to prevent absorbing oxygen and nitrogen from the atmosphere. The welding has been carried out under the welding conditions presented in Table 2. Three important factors of MPAW process chosen from literature are presented in Table 3. A large number of trail experiments are carried out using $1 \mathrm{~mm}$ thick AISI 316L stainless steel sheets to find out the feasible working limits of MPAW process parameters. Due to wide range of factors, it was decided to use three factors, namely plasma flow rate $F_{1}$, plasma current $I_{\mathrm{c}}$, and welding speed $S_{\mathrm{p}}$, with three levels for each factor. Face Centered central composite design matrix to specify the number of experiments for investigation was chosen. Table 4 includes the 20 set of coded conditions used to form the design matrix. The standard order " $S_{\mathrm{td}}$ " was randomized in order to minimize the unexpected variability in the observed response. The experimental conditions (rows) have been formed to meet main effects, corner points and center points. The method of designing such matrix is dealt with somewhere else ${ }^{12}$. For the convenience of recording and processing the experimental data, the upper and lower levels of the factors are coded as +1 and -1 , respectively and the coded values of any intermediate levels can be calculated by using the following fromula ${ }^{13)}$ :

$$
X_{i}=\frac{2 X-\left(X_{\max }+X_{\min }\right)}{X_{\max }-X_{\min }}
$$

Where $X_{\mathrm{i}}$ is the required coded value of parameter $X$ which is either $I_{\mathrm{c}}, S_{\mathrm{p}}$ or $F_{\mathrm{l}} . X$ belongs to the range $\left[X_{\max }-X_{\min }\right]$, where $X_{\min }$ is the lower limit the parameter and $X_{\max }$ is the upper limit of the parameter.

Table 1 Chemical composition of austenitic stainless steel sheets (wt\%).

\begin{tabular}{|c|c|c|c|c|c|c|c|}
\hline $\mathbf{C}$ & $\mathbf{S i}$ & $\mathbf{M n}$ & $\mathbf{P}$ & $\mathbf{S}$ & $\mathbf{C r}$ & $\mathbf{M o}$ & $\mathbf{N i}$ \\
\hline 0.024 & 0.46 & 1.29 & $<0.005$ & $<0.005$ & 16.50 & 2.03 & 10.06 \\
\hline
\end{tabular}


Table 2 Welding conditions.

\begin{tabular}{ll}
\hline Power source & Fronius micro plasma arc machine \\
\hline Model number & TransTIG 3000- Plasma Module 10 \\
Polarity & Direct current electrode negative (DCEN) \\
Mode of operation & Continues current (CC) \\
Electrode & $2 \%$ thoriated tungsten electrode \\
Electrode diameter & $2.4 \mathrm{~mm}$ \\
Plasma gas & Argon \\
Shielding gas & Argon \\
Shielding gas flow rate & $15 \mathrm{Lpm}$ \\
Purging gas & Argon \\
Purging gas flow rate & $0.4 \mathrm{Lpm}$ \\
Copper nozzle diameter & $2.4 \mathrm{~mm}$ \\
Nozzle to plate distance & $1 \mathrm{~mm}$ \\
Torch position & Vertical \\
Operation type & Automatic \\
\hline
\end{tabular}

Table 3 Important factors and their levels.

\begin{tabular}{ccccccc}
\hline & Input factor & Units & Symboll & $\mathbf{- 1}$ & $\mathbf{0}$ & $\mathbf{+ 1}$ \\
\hline 1 & Current & Amperes & $I_{\mathrm{c}}$ & 13 & 14 & 15 \\
2 & Speed & $\mathrm{cm} / \mathrm{min}$ & $S_{\mathrm{p}}$ & 18 & 20 & 22 \\
3 & Plasma flow & L/min & $F_{1}$ & 0.8 & 0.9 & 1.0
\end{tabular}

Table 4 Design matrix and experimental results.

\begin{tabular}{|c|c|c|c|c|c|c|c|}
\hline$S_{\mathrm{td}}$ & Run & $S_{\mathrm{p}}$ & $I_{\mathrm{c}}$ & $F_{1}$ & $\begin{array}{c}\text { Height } \\
H(\mathbf{m m})\end{array}$ & $\begin{array}{c}\text { Width } \\
W(\mathbf{m m})\end{array}$ & $\begin{array}{l}\text { HAZ } \\
(\mathrm{mm})\end{array}$ \\
\hline 1 & 1 & -1 & -1 & -1 & 0.384 & 1.655 & 0.041 \\
\hline 15 & 2 & 0 & 0 & 0 & 0.334 & 1.879 & 0.087 \\
\hline 5 & 3 & -1 & -1 & 1 & 0.436 & 1.871 & 0.067 \\
\hline 11 & 4 & 0 & -1 & 0 & 0.356 & 1.943 & 0.029 \\
\hline 8 & 5 & 1 & 1 & 1 & 0.415 & 1.849 & 0.069 \\
\hline 10 & 6 & 1 & 0 & 0 & 0.257 & 1.568 & 0.058 \\
\hline 4 & 7 & 1 & 1 & -1 & 0.292 & 1.685 & 0.052 \\
\hline 16 & 8 & 0 & 0 & 0 & 0.324 & 1.881 & 0.077 \\
\hline 9 & 9 & -1 & 0 & 0 & 0.432 & 2.024 & 0.169 \\
\hline 2 & 10 & 1 & -1 & -1 & 0.221 & 1.621 & 0.016 \\
\hline 18 & 11 & 0 & 0 & 0 & 0.279 & 1.895 & 0.092 \\
\hline 13 & 12 & 0 & 0 & -1 & 0.251 & 1.843 & 0.081 \\
\hline 3 & 13 & -1 & 1 & -1 & 0.497 & 2.206 & 0.178 \\
\hline 14 & 14 & 0 & 0 & 1 & 0.268 & 1.939 & 0.082 \\
\hline 7 & 15 & -1 & 1 & 1 & 0.704 & 2.294 & 0.189 \\
\hline 6 & 16 & 1 & -1 & 1 & 0.235 & 1.662 & 0.027 \\
\hline 17 & 17 & 0 & 0 & 0 & 0.302 & 1.802 & 0.075 \\
\hline 12 & 18 & 0 & 1 & o & 0.402 & 2.059 & 0.118 \\
\hline 20 & 19 & 0 & 0 & 0 & 0.282 & 1.875 & 0.079 \\
\hline 19 & 20 & 0 & o & o & 0.293 & 1.905 & 0.069 \\
\hline
\end{tabular}

\subsection{Measurement of Fusion Pool Geometry}

The metallurgical samples were cut at fusion pool, with the sample being located at $50 \mathrm{~mm}$ behind the trailing edge of the crater at the end of the fusion pool and has been mounted by using Bakelite. Preparing the samples and mounting them were done as in ASTM E 3-1 standard. The transverse faces of 
the samples were surface grounded using 120 grit size belt with the help of belt grinder. They were polished using grade 1/0 (245 mesh size), grade 2/0 (425 mesh size) and grade 3/0 (515 mesh size) sand paper. The specimens were further polished by initially using aluminum oxide and by utilizing diamond paste and velvet cloth in the polishing machine. The polished specimens were macro-etched by using $10 \%$ oxalic acid solution to reveal the fusion pool geometry to measure their parameters (Fig.1 and Fig. 2) by using metallurgical microscope (Make: Nikon Eclipse, Model No: E400 POL) at $\times 100$ magnification.

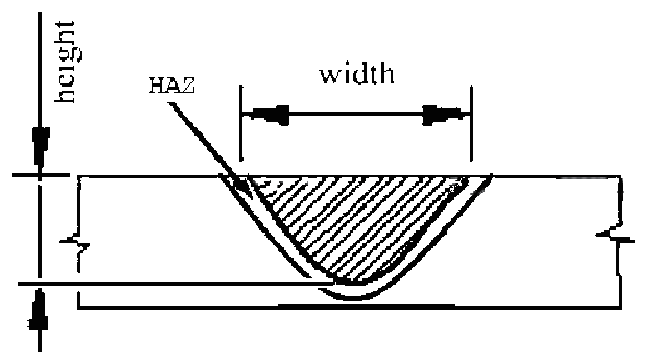

Fig. 1 Typical fusion pool geometry.

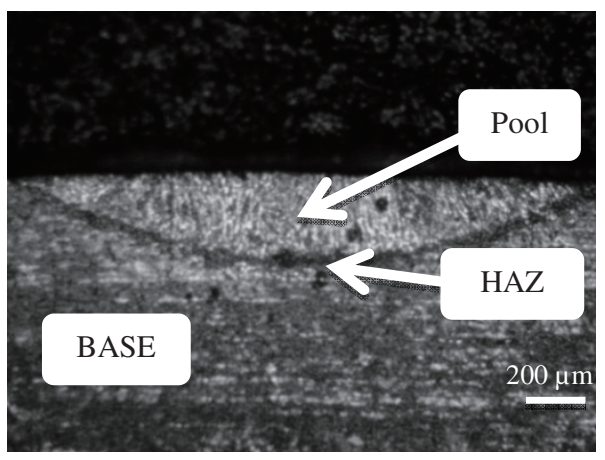

Fig. 2 Metallographic fusion pool.

3 Developing Mathematical Models

In most RSM problems ${ }^{13)-15)}$, the relationship between the response $(Y)$ and the independent variables is unknown. If the response is well modeled by a linear function then the approximating function is in the first order model.

$$
Y=b_{0}+\sum b_{i} x_{i}+\varepsilon
$$

Where $\varepsilon$ is the rest.

If interaction terms are added to main effects then the model is capable of representing some curvature.

$$
Y=b_{0}+\sum b_{i} x_{i}+\sum \sum b_{i j} x_{i} x_{j}+\varepsilon
$$

The curvature results from twisting the plane which is induced by the interaction term $b_{\mathrm{ij}} x_{\mathrm{i}} x_{\mathrm{j}}, i \neq j$.

If the curvature in the response function is not adequately modeled by Equation (3), then a logical model is considered.

$$
Y=b_{0}+\sum b_{i} x_{i}+\sum b_{i i} x_{i}^{2}+\sum \sum b_{i j} x_{i} x_{j}+\varepsilon
$$

Where $b_{\text {ii }}$ represents pure second order or quadratic effects. Equation (4) is a second order response surface model.

Using MINITAB 16 and Design Expert 10 statistical software to develop the final models with significant coefficients which correspond to the value of $P<0.05$, where $P$ is the level of significance as shown in Table 5.

$$
\begin{aligned}
& \text { Height }(H)=0.3-0.103 S_{p}+0.068 I_{c} \\
& +0.041 F_{l}+0.049 S_{p}{ }^{2}+0.084 I_{c}{ }^{2}+0.033 I_{c} F_{l} \\
& \text { Width }(W)=1.885-0.166 S_{p}+0.134 I_{c} \\
& +0.060 F_{l}-0.108 S_{p}{ }^{2}+0.096 I_{c}{ }^{2}-0.090 S_{p} I_{c} \\
& H A Z=0.084-0.0422 S_{p}+0.0426 I_{c} \\
& +0.023 S_{p}{ }^{2}-0.0169 I_{c}{ }^{2}-0.226 S_{p} I_{c}
\end{aligned}
$$

\section{Checking Adequacy of the Developed Models}

The adequacy of the developed models was tested using the analysis of variance technique (ANOVA) which is presented in Table 5, where the developed mathematical models are found to be adequate at $90 \%$ confidence level.

Table 5 Short ANOVA tables.

Short ANOVA for height

\begin{tabular}{|l|l|r|}
\hline$P$ & Term & Coefficient \\
\hline$<0.002$ & Constant & 0.299473 \\
\hline$<0.002$ & $S_{\mathrm{p}}$ & -0.103300 \\
\hline$<0.002$ & $I_{\mathrm{c}}$ & 0.0678000 \\
\hline 0.003 & $F_{1}$ & 0.0413000 \\
\hline 0.035 & $S_{\mathrm{p}}{ }^{2}$ & 0.0493182 \\
\hline 0.002 & $I_{\mathrm{c}}{ }^{2}$ & 0.0838182 \\
\hline 0.109 & $F_{1}{ }^{2}$ & -0.0356818 \\
\hline 0.201 & $S_{\mathrm{p}} I_{\mathrm{c}}$ & -0.0162500 \\
\hline 0.228 & $S_{\mathrm{p}} F_{1}$ & -0.0152500 \\
\hline 0.019 & $I_{\mathrm{c}} F_{1}$ & 0.0330000 \\
\hline
\end{tabular}

Short ANOVA for width

\begin{tabular}{|l|l|l|}
\hline$P$ & Term & Coefficient \\
\hline$<0.002$ & Constant & 1.885 \\
\hline$<0.002$ & $S_{\mathrm{p}}$ & -0.166 \\
\hline$<0.002$ & $I_{\mathrm{c}}$ & 0.1341 \\
\hline 0.015 & $F_{1}$ & 0.0605 \\
\hline 0.020 & $S_{\mathrm{p}}{ }^{2}$ & -0.108 \\
\hline 0.033 & $I_{\mathrm{c}}{ }^{2}$ & 0.096 \\
\hline 0.738 & $F_{1}{ }^{2}$ & -0.013 \\
\hline 0.003 & $S_{\mathrm{p}} I_{\mathrm{c}}$ & -0.090 \\
\hline 0.602 & $S_{\mathrm{p}} F_{1}$ & -0.012 \\
\hline 0.979 & $I_{\mathrm{c}} F_{1}$ & -0.0006 \\
\hline
\end{tabular}

Short ANOVA for HAZ

\begin{tabular}{|l|l|l|}
\hline$P$ & Term & Coefficient \\
\hline$<0.002$ & Constant & 0.0840 \\
\hline$<0.002$ & $S_{\mathrm{p}}$ & -0.0422 \\
\hline$<0.002$ & $I_{\mathrm{c}}$ & 0.0426 \\
\hline 0.099 & $F_{1}$ & 0.0066 \\
\hline 0.007 & $S_{\mathrm{p}}{ }^{2}$ & 0.0231 \\
\hline 0.035 & $I_{\mathrm{c}}{ }^{2}$ & -0.01686 \\
\hline 0.229 & $F_{1}^{2}$ & -0.00886 \\
\hline$<0.002$ & $S_{\mathrm{p}} I_{\mathrm{c}}$ & -0.0226 \\
\hline 0.787 & $S_{\mathrm{p}} F_{1}$ & -0.00113 \\
\hline 0.787 & $I_{\mathrm{c}} F_{1}$ & -0.00113 \\
\hline
\end{tabular}


Confirmation tests are carried out at different conditions to check the accuracy of the developed models. The details of confirmation tests and predicted values of the fusion pool geometry parameters are presented in Table 6 . However, the developed model is valid within the range of specified weld input parameters. Figures 3-5 indicate the scatter plots for fusion pool geometry parameters and reveal that the experimental and predicted values are close to each other within the specified limits.

Table 6 Confirmation test results.

\begin{tabular}{|c|c|c|c|c|c|c|c|c|c|c|c|}
\hline \multirow[b]{2}{*}{$S_{\mathrm{p}}$} & \multirow[b]{2}{*}{$I_{\mathrm{c}}$} & \multirow[b]{2}{*}{$F_{1}$} & \multicolumn{3}{|c|}{ Experimental } & \multicolumn{3}{|c|}{ Predicted } & \multicolumn{3}{|c|}{ Relative error } \\
\hline & & & $\begin{array}{l}\text { Height } \\
H(\mathrm{~mm})\end{array}$ & $\begin{array}{c}\text { Width } \\
W(\mathrm{~mm})\end{array}$ & $\begin{array}{l}\text { HAZ } \\
(\mathrm{mm})\end{array}$ & $\begin{array}{l}\text { Height } \\
H(\mathrm{~mm})\end{array}$ & $\begin{array}{c}\text { Width } \\
W(\mathrm{~mm})\end{array}$ & $\begin{array}{l}\text { HAZ } \\
(\mathrm{mm})\end{array}$ & $H$ & $W$ & HAZ \\
\hline-1 & -1 & 0 & 0.416 & 1.764 & 0.062 & 0.452 & 1.816 & 0.067 & 0.08 & 0.03 & 0.08 \\
\hline 0 & 1 & 1 & 0.466 & 2.011 & 0.096 & 0.490 & 2.162 & 0.106 & 0.05 & 0.07 & 0.09 \\
\hline-1 & 1 & 0 & 0.564 & 2.062 & 0.19 & 0.620 & 2.264 & 0.198 & 0.09 & 0.09 & 0.04 \\
\hline 1 & 0 & 1 & 0.227 & 1.546 & 0.056 & 0.236 & 1.645 & 0.062 & 0.04 & 0.06 & 0.10 \\
\hline
\end{tabular}

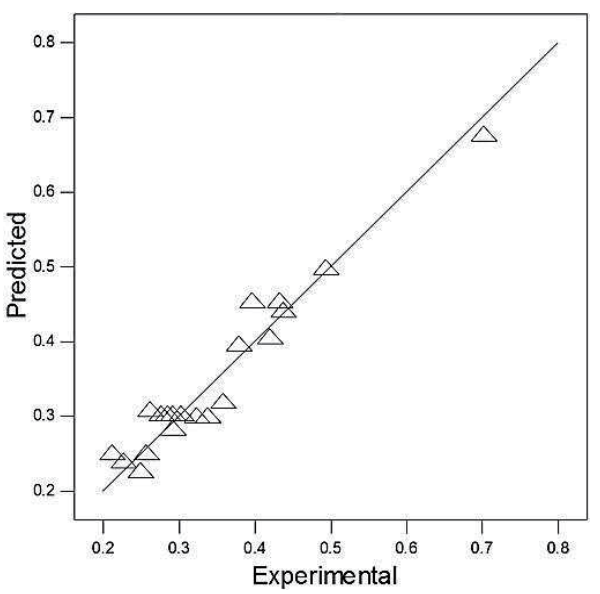

Fig.3 Scatter plot of height.

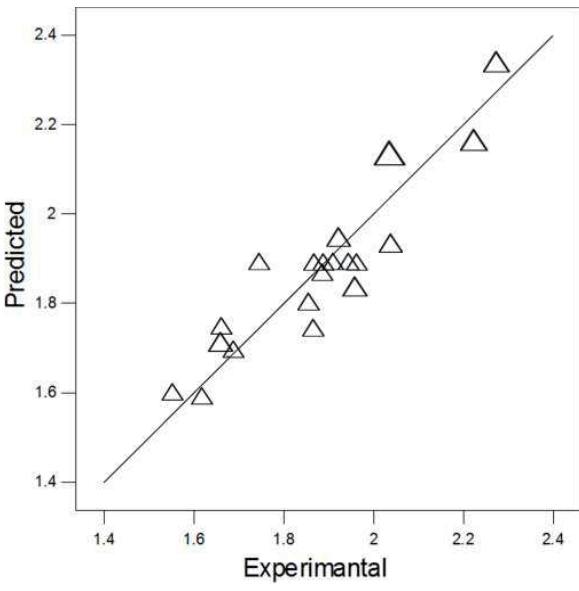

Fig.4 Scatter plot of width.

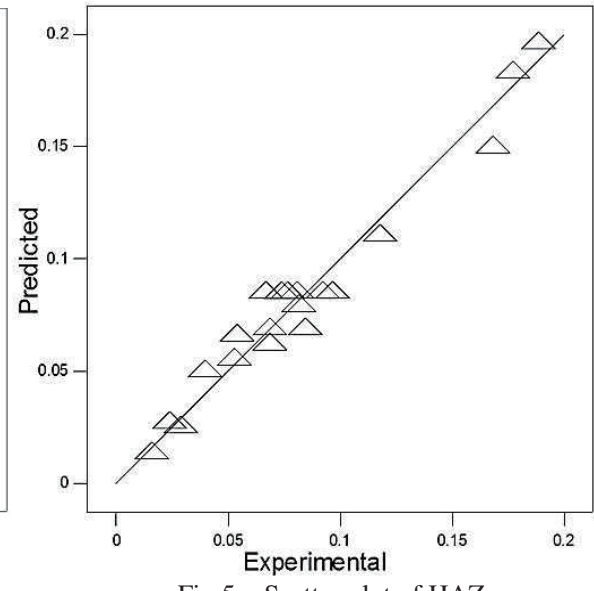

Fig.5 Scatter plot of HAZ.

\section{Results and Discussion}

The developed mathematical models above can be employed to predict the fusion pool geometry dimensions and their relationships for the range of parameters used in the investigation by substituting their respective values in coded forms. Based on these models, the effects of the process parameters on the fusion pool geometry dimensions are computed and plotted as shown in Fig. 6-11.

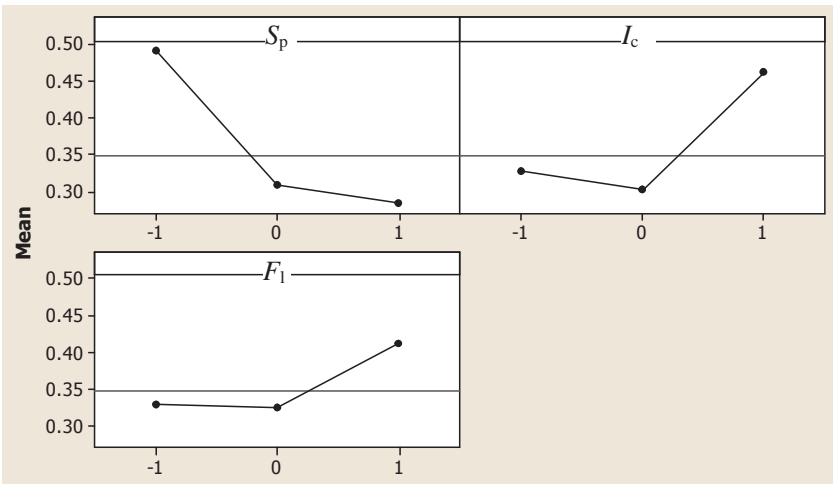

Fig. 6 Main effects for height.

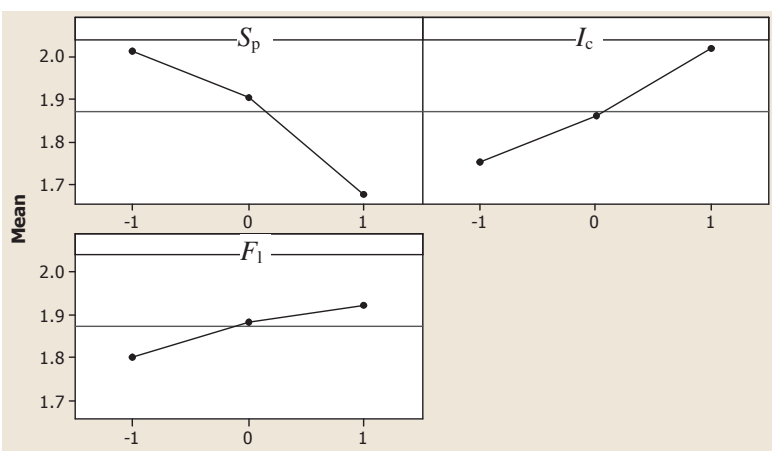

Fig.7 Main effects for width

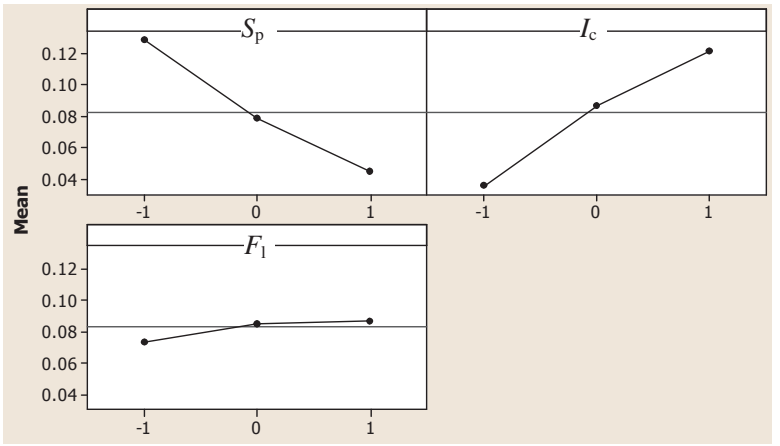

Fig.8 Main effects for HAZ's width. 


\subsection{Main effect}

The variations of fusion pool geometry parameters namely width, height and HAZ s width of AISI 316L fusion pool with MPAW input process parameters are presented in Fig. 6, Fig. 7 and Fig. 8. Width, height and HAZ`s width parameters decrease in relation based on welding speed as heat input decreases. Height decreases slowly, but only a little bit with current from -1 to 0 coded values, then beyond it, the height increases. For width and HAZ, both increase with current in different rates. At lower current, up to coded value -1, the heat input is less and hence low melting rate of the parent metal leads to lower width and HAZ. When the current increases beyond coded value -1 , the heat input also increases and hence high melting rate of base metal leads to higher width and HAZ. As the flow rate is helpful in maintaining continuous arc during welding, when the flow rate is high up to coded value 1 , height, width and HAZ increase due to high and dominant current which generates large amount of heat.

\subsection{Interaction effect}

Contour plots play a very important role in the study of the response surface method. By generating contour plots using
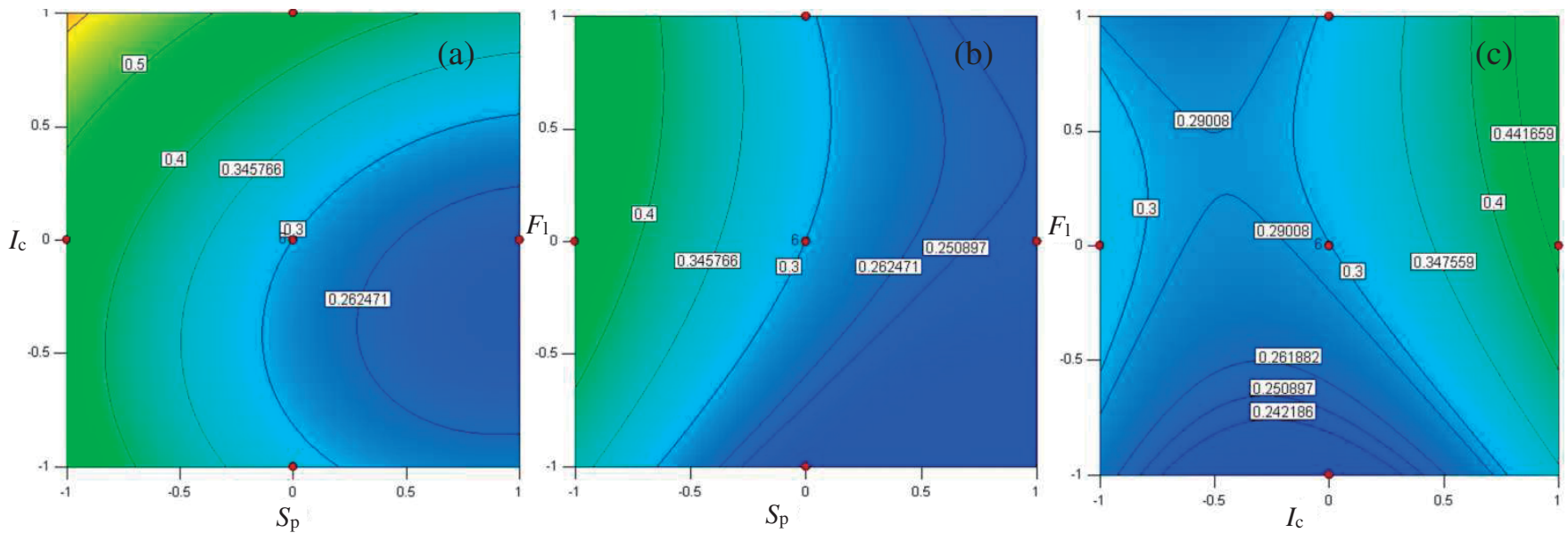

Fig. 9 Contour plots of $H$; (a) $I_{\mathrm{c}}$ and $S_{\mathrm{p}}$, (b) $F_{1}$ and $S_{\mathrm{p}}$, (c) $F_{1}$ and $I_{\mathrm{c}}$.
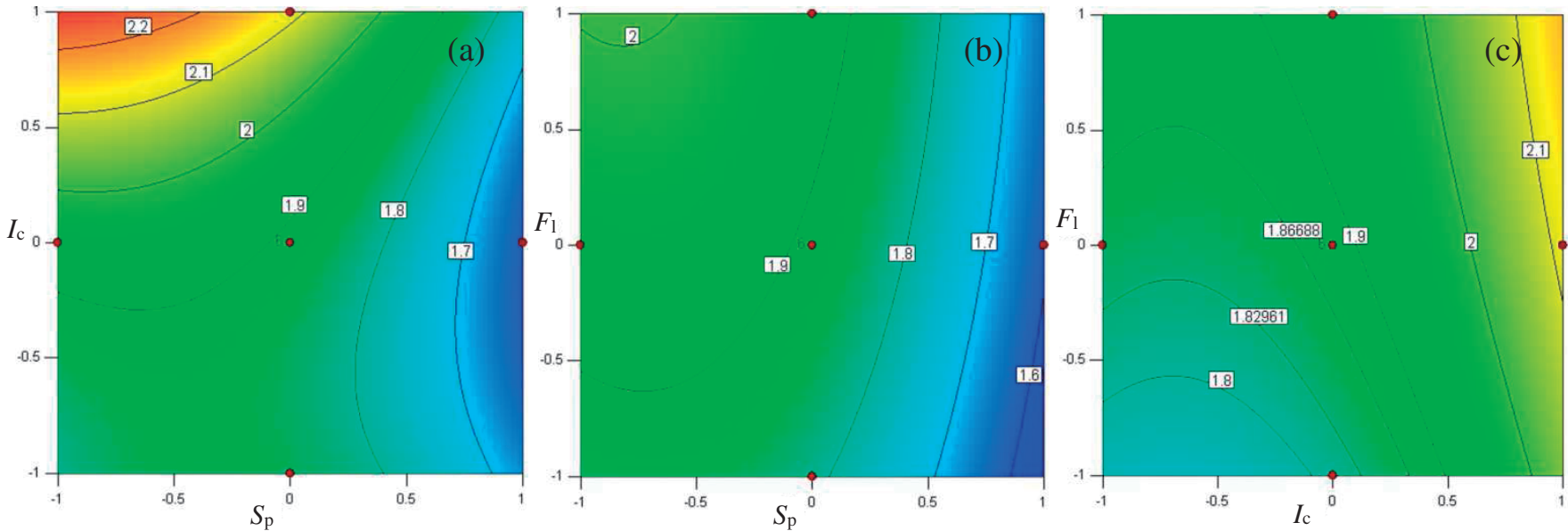

Fig. 10 Contour plots of $W$; (a) $I_{\mathrm{c}}$ and $S_{\mathrm{p}}$, (b) $F_{1}$ and $S_{\mathrm{p}}$, (c) $F_{1}$ and $I_{\mathrm{c}}$.
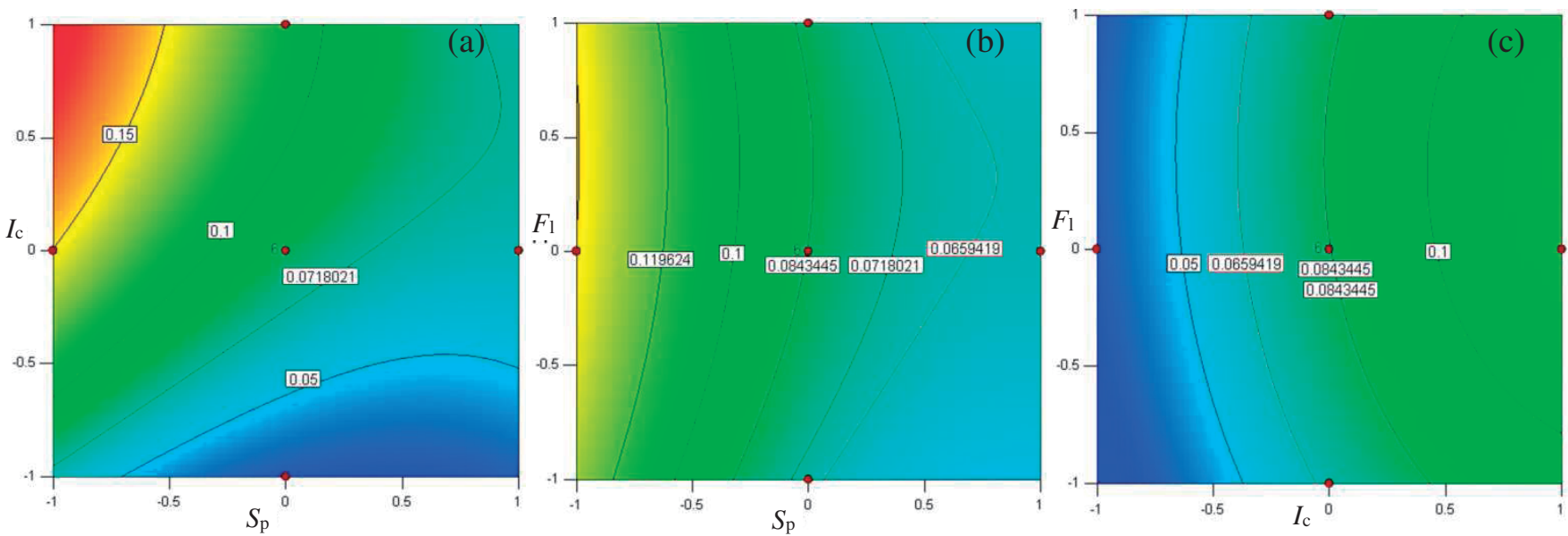

Fig. 11 Contour plots of HAZ; (a) $I_{\mathrm{c}}$ and $S_{\mathrm{p}}$, (b) $F_{1}$ and $S_{\mathrm{p}}$, (c) $F_{1}$ and $I_{\mathrm{c}}$. 


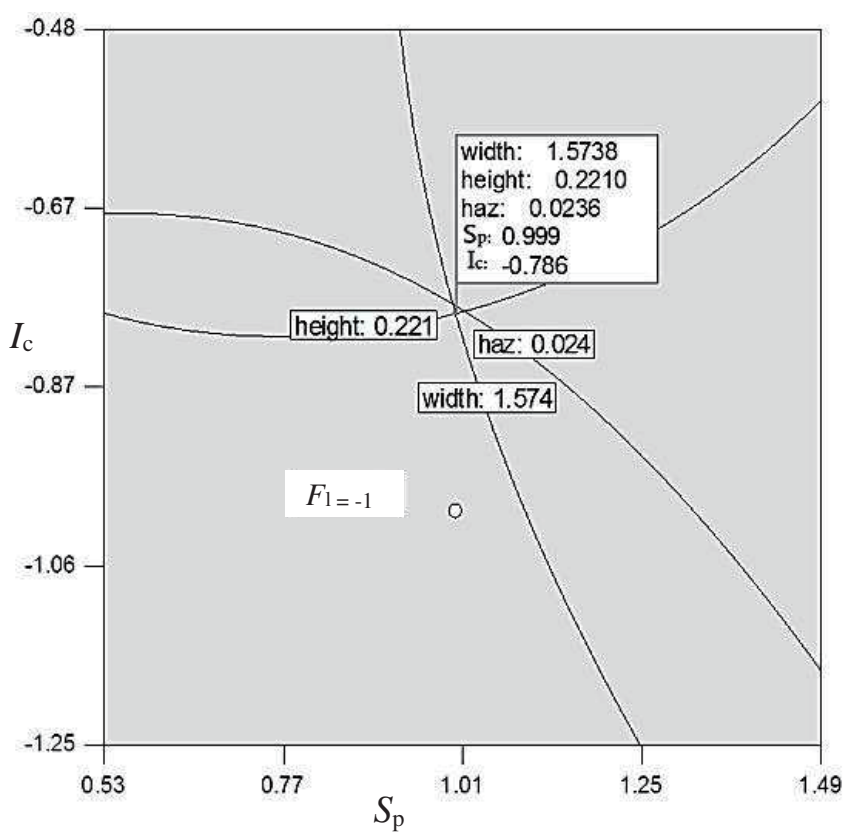

Fig. 12 Graphical optimization.

Table 7 Optimal point characteristics.

\begin{tabular}{|c|c|c|c|c|c|}
\hline Width & Height & HAZ & $\boldsymbol{S}_{\mathbf{p}}$ & $\boldsymbol{I}_{\mathbf{c}}$ & $\boldsymbol{F}_{\mathbf{1}}$ \\
\hline 1.574 & 0.221 & 0.024 & 1.00 & -0.786 & -1.00 \\
\hline
\end{tabular}

software (Design Expert 10) for response surface analysis, the optimum is specified by characterizing the shape of the surface. If circular contours occur, this suggests the independence of factor effects; while elliptical contours may indicate factor interaction. Figures 9(a), (b) and (c) represent the contour plots for height and Figs. 10(a), (b) and (c) represent the contour plots for width, whereas Figs. 11(a), (b) and (c) represent contour plot for HAZ's width. From the contour plot in Fig.9(a), it can be seen that height is more sensitive to speed than to current. From Fig.9(b), it is clear that speed affects height more than flow rate. From Fig.9(c), it can be seen that height is sensitive to both flow rate and current. The contour plot in Fig.10(a) shows that width is sensitive to both speed and current. From Fig.10(b), it can be seen that width is more sensitive to speed than to flow rate, whereas Fig.10(c) shows that width is more sensitive to current than to flow rate. From Fig.11(a), it can be seen that HAZ is sensitive to both speed and current. From Fig.11(b), it is clear that HAZ's width is more sensitive to speed than to flow rate, whereas Fig.11(c) shows that HAZ's width is more sensitive to current than to flow rate. All the contour plots prove that speed and current are the most important factors which affect the pool geometry parameters of stainless steel AISI 316L.

The optimum pool geometry is achieved when HAZ and width become narrower and height gets lower. The optimal response point can be calculated by the software (Design
Expert 10), as shown in Fig. 12 and explained in Table 7.

\section{Conclusions}

Three factors (speed, current, flow rate), three levels ( -1 , $0,+1)$, full factorial design matrix based on the central composite, face centered design technique were used for the development of mathematical models to predict the fusion pool geometry parameters for AISI316L stainless sheets by micro plasma arc welding process. By using mathematical models, the most predicted results are very close to the experimental ones. It is proved that pool parameters are sensitive to speed and current. Speed is the most dominant factor out of the selected factors, since when speed decreases, heat input decreases leading to narrow width, low height and small HAZ. The optimal fusion pool is achieved when the welding speed is coded value 1 , current is coded value -0.786 and flow rate is coded value -1 .

\section{References}

1) N. Arivazhagan, S. Singh, S. Prakash and G.M. Reddy, "Investigation on AISI 304 austenitic stainless steel to AISI 4140 low alloy steel dissimilar joints by gas tungsten arc, electron beam and friction welding", Materials and Design, Vol. 32, No.5, pp.3036-3050 (2011).

2) T. D. Clark, Department of Mechanical Engineering, Master's Thesis, Brigham Young University, Provo, (2005).

3) D. K. Zhang and J. T. Niu, "Application of artificial neural network modeling to plasma arc welding of aluminum alloys", Journal of Advanced Metallurgical Sciences, Vol. 13, No. 1, pp. 194-200 (2000).

4) S.-C. Chi and L.-C. Hsu, "A fuzzy radial basis function neural network for predicting multiple quality characteristics of plasma arc welding", Joint 9th IFSA World Congress and 20th NAFIPS International Conference, Vancouver, 25-28 July, pp. 2807-2812 (2001).

5) Y. F. Hsiao, Y. S. Tarng and W. J. Huang, "Optimization of plasma arc welding parameters by using the taguchi method with the grey relational analysis", Journal of Materials and Manufacturing Processes, Vol. 23, No. 1, pp. 51-58(2007).

6) K. Siva, N. Murugan and R. Logesh, "Optimization of weld bead geometry in plasma transferred arc hardfaced austenitic stainless steel plates using genetic algorithm", International Journal of Advanced Manufacturing Technology, Vol. 41, No. 1-2, , pp. 24-30 (2008).

7) A. K. Lakshminarayanan, V. Balasubramanian, R. Varahamoorthy and S. Babu, "Predicting the dilution of plasma transferred arc hardfacing of stellite on carbon steel using response surface methodology", Metals and Materials International, Vol. 14, No. 6, pp. 779-789 
(2008).

8) V. Balasubramanian, A. K. Lakshminarayanan, R. Varahamoorthy and S. Babu, "Application of response surface methodology to prediction of dilution in plasma transferred arc hardfacing of stainless steel on carbon steel”, International Journal of Iron and Steel Research, Vol. 16, No. 1, pp. 44-53 (2009).

9) E. Taban, A. Dhooge and E. Kaluc, "Plasma arc welding of modified $12 \% \mathrm{Cr}$ stainless steel", Materials and Manufacturing Processes, Vol. 24, No. 6, pp. 649-656 (2009).

10) N. Kahraman, M. Taskin, B. Gulenc and A. Durgutlu, "An investigation into the effect of welding current on the plasma arc welding of pure titanium", Kovove Materialy, Vol. 48, No. 3, pp. 179-184 (2010).

11) N. Srimath and N. Muragan, "Prediction and optimization of weld bead geometry of plasma transferred arc hardfacing valve seat rings", European Journal of Scientific Research, Vol. 51, No. 2, pp. 285-298 (2011).

12) D. C. Montgomery, "Design and analysis of experiments", 3rd Edition, (1991) John Wiley \& Sons, New York.

13) G. E. P. Box, J. S. Hunter and W. G. Hunter, "Statistics for experiments", (1978) John Wiley \& Sons, New York.

14) T. B. Barker, "Quality by experimental design”, (1985) ASQ Press, Milwaukee.

15) W. P. Gardiner and G. Gettinby, "Experimental design techniques in statistical practice", (1998) Horwood Publishing, Chichester. 